\title{
Comerciantes e artesãos toscanos nas ruas de São Paulo (1875-1914)
}

Merchants and Tuscan craftsmen in the streets of São Paulo (1875-1914)

Antonio de Ruggiero*

\section{Resumo}

Este artigo pretende reconstruir a contribuição de um fluxo migratório oriundo da região italiana da Toscana, na capital paulista, no período conhecido como "Grande Imigração" (1875-1914). Embora nas estatísticas oficiais a região não apareça entre as primeiras regiões de êxodo da península no período referenciado, o papel dos toscanos nos contextos urbanos brasileiros foi significativo. Em particular, na cidade de São Paulo esse grupo representou uma das mais numerosas comunidades regionais. O estudo evidencia uma propensão para o exercício de trabalhos artesanais "qualificados" e para o comércio de produtos étnicos importados da terra de origem. Em ambos os casos, esses imigrantes conseguiram construir redes sociais que permitiram a manutenção de uma ligação estreita entre o país de proveniência e o país receptor.

Palavras-chave: Emigração italiana ao Brasil; Emigração toscana; Urbanização; São Paulo.

\begin{abstract}
This article intends to reconstruct the contribution of a migratory flow arising from Italian region of Tuscany to São Paulo in the period known as the "great migration" (1875-1914). Although the official statistics the region doesn't appear among the first exodus of peninsula's regions, in the referenced period the role of Tuscans in Brazilian urban contexts was significant. In São Paulo city particularly, that group was one of the largest regional communities. The study reveals a propensity for the "qualified" craftwork and the commerce of ethnic products imported from the native land. In both cases, these immigrants managed to establish social networks that made possible maintaining a close link between the country of origin and the host country.
\end{abstract}

Keywords: Italian emigration to Brazil; Tuscan Emigration; Urbanization; São Paulo.

\section{Introdução}

Falar de emigração toscana ao Brasil significa referir-se a uma tipologia migratória peculiar e diferenciada em relação às grandes massas de emigrantes italianos que, no último quartel do século XIX, dirigiram-se, primeiro em direção às localidades agrícolas dos estados do Sul, Rio Grande do Sul, Paraná e Santa Catarina e, sucessivamente, em direção às fazendas das chamadas “Terras do café”, em São Paulo e

\footnotetext{
* Doutor em História Moderna e Contemporânea pela Università degli Studi di Firenze. Pós-doutor pela Pontifícia Universidade Católica do Rio Grande do Sul. Professor do Programa de Pós-graduação em História da Pontifícia Universidade Católica do Rio Grande do Sul (PUCRS). Membro da Associação Internacional Audioarchivio delle migrazioni tra Europa e América Latina (AREIA).
} 
no sul de Minas Gerais. Generalizando-se ao máximo, pode-se afirmar que os italianos mais famintos de terra escolheram o Brasil em virtude das políticas rurais atrativas no país de acolhida. minhas pesquisas demonstraram que a vocação de tal grupo regional pareceu desde cedo menos vinculada à exclusiva ocupação agrícola. Cerca de 80.000 toscanos, que desembarcaram nos portos brasileiros durante o período da "grande emigração", ao contrário, marcaram significativamente alguns centros urbanos principais que assistiram, entre o fim do século XIX e o início do século seguinte, a um processo de transformação social, expansão e modernização, ligado de modo tangível ao incremento da emigração europeia (DE RUGGIERO, 2011).

Essa característica se liga, também, ao fato de o fenômeno migratório ter-se referido, desde o Ancien Régime, à região sub-apenínica norte-ocidental, sobretudo àquelas áreas que ficaram excluídas do sistema de parceria, distintas por uma excessiva fragmentação da terra e caracterizadas, além disso, por uma antiga tradição de mobilidade sazonal ligada ao desenvolvimento de trabalhos tidos como itinerantes e por pequenos comércios ambulantes. Estes são elementos distintivos que se repetiram de forma e em medida diferentes também nas migrações transoceânicas mais duradouras do fim do século XIX.

\section{Toscanos em São Paulo}

A cidade de São Paulo, que atualmente pode ser definida como a principal cidade "italiana" fora da Itália, merece uma atenção especial porque foi caracterizada por uma marca regional toscana muito visível e incisiva. No final do século XIX, se desenvolveu um setor manufatureiro urbano que passou a produzir aquilo que antes criava-se no campo e que substituiu em parte aquele das fazendas e do campo (VANGELISTA, 1981). Isso aconteceu, também, em consequência da pressão demográfica exercida pelos emigrantes europeus mais especializados e menos submissos em relação aos braços para a cafeicultura (TRENTO, 1984).

Existe uma válida literatura de viagem relativa ao principal centro da emigração italiana no Brasil que, entre o século XIX e XX, enriqueceu as notícias e as percepções sobre a cidade e que, em alguns casos, serviu como estímulo e, em outros, como advertência geral para os outros italianos, com intenção de emigrar em direção ao país sul-americano, sendo atualmente instrumento indispensável para uma análise mais completa do fenômeno de emigração urbana. Os numerosos relatos contemporâneos de 
viajantes e, muitas vezes, jornalistas na roupagem de enviados especiais, de fato, permitiram delinear um perfil mais coerente sobre os usos, os costumes sociais e os caracteres salientes dos italianos nos países de acolhimento. Além disso, esclareceramse mais a divisão regional e a distribuição nas várias profissões desenvolvidas.

No caso do doutor Alfonso Lomonaco (1889), autor em 1885 de um detalhado diário de viagem ao Brasil, se reúnem, por exemplo, preciosas notícias relativas às condições econômicas e sociais e à vida quotidiana nos mais importantes centros do país. Ele dedicou também uma atenção especial à cidade que, mais do que as outras, teria adquirido um caráter de profunda italianidade. Caminhando pelas ruas centrais de São Paulo, o viajante italiano destacava, já à época, a presença de um consistente grupo de trabalhadores provenientes da Toscana.

A mesma percepção era confirmada pela médica Gina Lombroso Ferrero, filha do mais conhecido Cesar Lombroso e esposa do conhecido jornalista Guglielmo Ferrero, que em 1908 visitou as comunidades italianas no Brasil. Ficou impressionada quando, passeando no centro da capital paulista, se sentiu praticamente em casa, dada a influência também linguística que seus compatriotas emigrantes, especialmente toscanos e vênetos, exerciam no comércio e nas várias profissões:

O traço mais saliente da cidade é a sua italianidade. Se sente mais italiano em São Paulo do que em Turim, em Milão ou em Nápoles, porque enquanto entre nós se fala em dialeto, em São Paulo todos os dialetos se fundem sob a influência dos Vênetos e dos Toscanos, que são a maioria. (MARTINELLI, 1988, p. 93). ${ }^{1}$

De fato, o crescimento demográfico de São Paulo resultou impressionantemente em relação aos fluxos emigratórios europeus, em uma preponderância daqueles italianos. Basta pensar que os 23.243 habitantes de 1872 tornaram-se aproximadamente 65.000 em 1890, para subir vertiginosamente a $130.000 \mathrm{em} \mathrm{1893;} \mathrm{a} 240.000 \mathrm{em} 1900$ e a aproximadamente 400.000 às vésperas da Primeira Guerra Mundial, quando os italianos representavam mais da metade da população adulta masculina (TRENTO, 2000). Por esse motivo, a historiografia, abordando o tema da emigração italiana ao Brasil, sempre individuou na comunidade de São Paulo um modelo de comparação necessário para compreender a emigração italiana no mundo (BIONDI, 2002, p. 24). Para quem se ocupa de emigração toscana, como eu próprio, essa capital brasileira tem

\footnotetext{
${ }^{1}$ Martinelli (1988) faz referência a Gina Ferrero Lombroso (1908), Nell'America Meridionale (BrasileUruguay-Argentina).
} 
um interesse totalmente particular, pois foi caracterizada desde o último quarto do século XIX por tal marca regional em diversos setores profissionais.

Já em 1882, quando ainda deviam começar os grandes fluxos organizados da emigração em direção às plantações de café, a cidade, que contava com apenas 35.000 habitantes, era considerada "cosmopolita" pela presença de alemães, franceses, ingleses, portugueses e 12.000 italianos. Como revelava o diplomata italiano Alberto De Foresta (1884, p. 283), cerca de um terço destes últimos, isto é, aproximadamente quatro mil, "deviam ser somente os originários de Lucca".

Embora o dado numérico deva ser tomado com a necessária prudência, damonos conta do tamanho da influência, já naquela época entre os italianos na cidade, da comunidade proveniente das circunscrições do antigo Ducado de Lucca que, na realidade, compreendia também o território apenínico mais amplo de Garfagnana e de Lunigiana, na maior parte dos casos formada por indivíduos sem família, não vinculados ao solo e, portanto, propensos a contínuos retornos à pátria e a manter, contudo, com o próprio lugar de origem constantes relações de negócios. Tanto que, justamente no mesmo período, o prefeito da cidade pressionava o Ministério do Exterior a fim de que, ao consulado brasileiro em Livorno, se acrescentasse outro também em Lucca (BRIGANTI, 1997).

De Foresta (1884, p. 282) evidenciava a propensão "urbana" dos imigrantes de Lucca que, no caso de São Paulo, gozavam de "maior prosperidade" e se distinguiam pela ocupação em diversos setores comerciais e artesanais. Muitos deles, "feito o pecúlio", após alguns anos podiam retornar à pátria, diferentemente dos tantos camponeses sulistas que viviam nos campos da periferia e, enganados e seduzidos "pelo sonho da América", haviam se "sepultado nestas regiões longínquas", colhendo “dificuldades, lágrimas e dores".

\section{Enclaves comerciais e circuitos empreendedores}

Se o comércio maior na cidade ainda estava nas mãos da colônia alemã, ao passo que os poucos franceses eram na maioria proprietários de pequenas lojas de luxo e ateliês de costura e os ingleses empregados nas numerosas companhias para a construção das ferrovias, já se começavam a definir entre os italianos as diversas profissões exercidas. Tal presença étnica pioneira na cidade representou um estímulo 
importante e um ponto de referência nos anos sucessivos para quem, proveniente dos mesmos territórios da região, tentou a sorte no Brasil.

De fato, o antigo costume dos deslocamentos permitira para alguns vanguardistas provenientes da área apenínica e, sobretudo, de Lucca, criar em algumas cidades brasileiras verdadeiras e próprias enclaves comerciais e empreendedoras já nos anos precedentes às grandes políticas de acolhimento de mão de obra europeia. Isso favoreceria a formação e o fortalecimento de redes sociais úteis à inserção profissional de muitos conterrâneos nas emigrações sucessivas. E, ainda mais, permitiu a esse grupo regional ocupar os pontos mais estratégicos para abrir comércios e pequenas empresas dedicadas em muitos casos ao artesanato, mas ainda mais à venda de produtos "étnicos" importados da própria região, que podia oferecer uma grande variedade de azeite, vinho, queijo, etc.

O caso dos originários de Lucca, em especial, pode ser considerado emblemático na história da emigração italiana e avalizar as intuições de quem, como Amoreno Martellini (2009), evidenciou a importância exercida pelo funcionamento de robustas redes relacionais e de proteção para agilizar o risco de empresa de muitos compatriotas no exterior. Em suma, redes sociais consolidadas há anos permitiram a formação de verdadeiros "circuitos empreendedores" que, no caso específico, encontraram uma expressão tangível nas principais cidades brasileiras envolvidas pelo fenômeno migratório italiano no fim do século XIX.

Não só entre os toscanos, mas em bom número entre esses provenientes, muitas vezes dos vilarejos apenínicos da Garfagnana e Lunigiana na fase pioneirista da imigração italiana no Brasil, se reencontrou depois, seja em São Paulo, seja no Rio Grande do Sul, a presença da característica figura do comerciante ambulante, ou seja, do vendedor ambulante chamado pelos brasileiros de mascate.

O cônsul italiano em Porto Alegre, Compans de Brichanteau, em 1892 traçava um retrato confiável desses incansáveis trabalhadores que, diferentemente da grande maioria de camponeses nortistas chegados para ocupar as colônias agrícolas postas à disposição pelo governo brasileiro, a partir de 1875, chegaram ao novo mundo sem família para tentar a sorte por meio do comércio ambulante naquelas terras que, isoladas dos principais centros urbanos, estavam sendo povoadas por famílias camponesas italianas: 
Estes, conseguindo a crédito do comerciante atacadista uma certa quantidade de mercadorias e de gêneros mais diversos, que reúnem em uma caixa adequada em vidro, com este peso nos ombros, caminham sob o açoite do sol por muitas léguas e vendem no interior e nos lugares mais isolados a própria mercadoria; depois voltam à cidade quando a provisão acabou, pagam ao comerciante aquilo que lhe é devido e, reabastecidos, partem novamente. Tal ofício dificilíssimo dá, em geral, um enorme lucro e a maior parte dos nossos comerciantes não começaram de outra forma a sua fortuna atual. (COMPANS DE BRICHANTEAU, 1893, p. 111).

Alguns deles, que se abasteciam nos estabelecimentos de grandes comerciantes, muitas vezes provenientes da mesma região, após terem acumulado um lucro que podia inclusive ser discreto, retornavam à pátria. Em muitas outras circunstâncias analisadas, porém, tal atividade representava somente a primeira etapa de uma parábola ascendente que permitia ao imigrado a construção de pequenas fortunas econômicas ou, contudo, de atividades comerciais mais ou menos rentáveis e estáveis nas principais cidades de emigração italiana.

No caso de São Paulo, entre as tantas, é exemplar a experiência de Pasquale de Ranieri que, nos primeiros anos do século $\mathrm{XX}$, abriu uma casa comercial importadora de produtos exclusivamente italianos, entre os quais artigos de secretaria, pipas, tecidos, botões e quinquilharias diversas. Junto à atividade comercial estabeleceu também uma fábrica de chapéus de palha, que lhe garantia milhares de clientes em São Paulo e no interior do Estado.

Como recitava um artigo abundantemente retórico publicado num almanaque de 1924, tratava-se de uma trajetória migratória de sucesso, "que merece(ia) muitos aplausos". Nascido em Santa Maria del Giudice, na província de Lucca, Ranieri chegou ao Brasil sem familiares, "sem meios e sem recursos", com apenas 13 anos. Começou a sua atividade de comerciante ambulante com um saco no ombro, reabastecendo-se na loja de um compatriota e passando os dias vendendo, nos mais longínquos bairros de São Paulo e nas cidades vizinhas, objetos de secretaria e quinquilharias. $\mathrm{Na}$ sua descrição biográfica lê-se:

Aquele trabalho durou muitos anos, mas foi providencial, porque permitiu ao ambulante adquirir uma grande prática do comércio e uma completa experiência das condições locais. E ei-lo de fato subir de grau: em 1909 começa a fazer parte da Empresa Fratelli Del Guerra que realizava em ampla escala o mesmo comércio. [...] Foi assim que um ano depois, em 1910, abriu no Bairro do Cambucy a sua primeira casa comercial que transferiu, depois, ao Braz e, finalmente, na sua atual sede na Rua Florêncio de Abreu. (GLI ITALIANI, 1924, p. 125). 


\section{O comércio étnico}

De toda a experiência migratória do originário de Lucca, se destacava, principalmente, o mérito de introduzir no Brasil artigos de produção italiana e, de fato, em grande parte toscana. Isso acomunava Ranieri a muitos outros seus compatriotas que, no período da grande migração, estabelecidos os contatos com amigos ou parentes já residentes no país, após uma primeira fase de trabalho dependente, conseguiram estabelecer na cidade atividades comerciais que se mantinham graças à contínua importação de mercadorias da Itália.

Nos estudos mais atuais sobre o fenômeno das migrações humanas que, no contexto da globalização, adquiriram grande força em nível multidisciplinar, se acentuou notavelmente o debate em torno do conceito de "transnacionalismo", que a socióloga norte-americana Glick Schiller definiu como "o processo mediante o qual os emigrantes constroem campos sociais que ligam o país de origem àquele de destino".

O sociólogo italiano Maurizio Ambrosini (2009) focalizou especificamente no "transnacionalismo econômico", nas hodiernas emigrações, evidenciando como, ao lado do imponente fenômeno das remessas, outro lugar relevante é ocupado pelas iniciativas empreendedoras "de baixo", da parte daqueles indivíduos que ele define como "formigas da globalização", isto é, emigrantes que mobilizam os próprios contatos por meio das fronteiras, em busca de novos mercados e possibilidades.

Meritoriamente a historiadora Paola Corti (2009) analisou tal categoria inserida também nas mais antigas emigrações italianas e, em especial, no período do êxodo de massa, quando muitas experiências analisadas referem-se à criação de vínculos sociais, de network e formas de comunicação, que permitem a proliferação de pequenas redes empreendedoras de caráter transnacional. Isso foi evidente no caso do comércio de importação exercido, muitas vezes com sucesso, na capital paulista por muitos toscanos.

As numerosas fotografias recolhidas no Arquivo Paolo Cresci de Lucca nos mostram que, nas vitrines de muitas lojas abertas por originários de Lucca, se escrevia orgulhosamente que os produtos vendidos caracterizavam-se pela genuinidade e pela autêntica proveniência "de Lucca", ou mais em geral "toscana" (OSTUNI, 2001). O mesmo valia para o discreto número de importadores florentinos que patrocinavam, também por meio das páginas dos mais importantes jornais da colônia italiana, o vinho 
diretamente proveniente do território de Chianti. O discurso era similar para os tecidos e os chapéus chamados "florentinos".

O caso da emigração toscana nos principais centros urbanos brasileiros pode ser considerado emblemático nesse sentido. Não é somente o caso de lembrar um empreendedorismo reconhecido e estereotipado frequentemente por meio dos lugares comuns sobre "tios da América", ou sobre os self mademen, como por exemplo o grande magnata, natural de Lucca, Giuseppe Martinelli, que em poucos anos, por meio de investimentos de capital, ampliou o seu círculo de negócios tornando-se o maior importador de produtos italianos no Brasil, criando um império industrial que tinha filiais nos setores bancários, de navegação e de construção pública. Antes, é útil evidenciar entre os toscanos a presença de um considerável grupo de pequenos ou microinvestidores que, depois de um início difícil, se fortaleceram e ampliaram a própria atividade, até ocupar de modo predominante alguns setores estratégicos (FRANZINA, 2007).

As vanguardas de Lucca estabelecidas em algumas cidades como São Paulo contribuíram notavelmente à instalação de novos exercícios, desde os primeiros desenvolvimentos urbanos, em determinados âmbitos da vida comercial. Nos anos sucessivos, a componente migratória toscana pôde beneficiar-se sempre mais das estreitas ligações com a região de origem, para empreender atividades de comércio étnico por meio da importação de produtos alimentícios típicos, como azeite, vinho e queijo, mas também de tecidos finos ou chapéus, assim como do prestigiado mármore de Carrara, muito utilizado nas novas construções da alta burguesia urbana do fim do século. A essa demanda se seguia uma necessária mão de obra qualificada como artesanal proveniente dos territórios das pedreiras de mármore.

Os dados recolhidos por Salvatore Pisani relativamente à cidade de São Paulo nos anos 30 do século XX, representavam em grandes linhas a subdivisão regional das atividades desenvolvidas pelos compatriotas. Enquanto os sulistas haviam se especializado no pequeno comércio e em alguns ofícios e artes, e os nortistas, na criação de pequenas e grandes indústrias, bem como os empregos nas fábricas, os toscanos ocupavam na maior parte o setor do "comércio de importação" e "do comércio em geral”. Alguns deles começaram com modestas iniciativas comerciais para empreender,

\footnotetext{
2 Significativas nesse sentido são as páginas do jornal quotidiano da comunidade ítalo-paulista, o Fanfulla. Nos anos do nosso interesse, nas páginas dedicadas às atividades comerciais urbanas abertas por compatriotas, ao lado do nome do proprietário, se especificava quase sempre a proveniência regional e a caracterização típica dos produtos vendidos.
} 
a seguir, atividades microindustriais com a abertura de moinhos, fábricas de massa, de chapéus, empresas de construção civil e outras menos significativas do ponto de vista numérico (PISANI, 1937, p. 1047).

A predominância do comércio de importação em São Paulo durou pelo menos até 1914. Já os primeiros italianos que chegaram à cidade, e entre eles uma parte conspícua de originários de Lucca, eram em boa parte pequenos comerciantes que esperavam poder continuar exercendo in loco a própria habitual atividade, com a perspectiva de incrementar rapidamente as economias. Entre os pioneiros, alguns tentaram colocar no mercado produtos novos, sobretudo gêneros alimentícios diretamente trazidos da Itália.

Isso aconteceu predominantemente nos anos mais intensos da emigração italiana ao exterior, quando o primeiro-ministro italiano Francesco Crispi tentava favorecer e valorizar ao máximo aquele fenômeno de "mercado induzido", que permitiria uma penetração mais consistente de produtos italianos nas várias "Itálias fora da Itália". São Paulo se prestava a esse objetivo, considerando o número sempre crescente de compatriotas residentes e o fato de que, na cidade brasileira, as poucas indústrias agrícolas presentes no final do século XIX estavam quase exclusivamente ligadas à manufatura do café, do açúcar ou do algodão.

Os comerciantes italianos encontraram um terreno propício para comercializar com maior facilidade vinhos, queijos e azeites característicos da península, que gozavam de grande reputação pela qualidade e genuinidade. Graças a poucos iniciadores nesse setor, estabeleceu-se entre a Itália e o Brasil uma primeira corrente de negócios, favorecida pelo baixo custo dos artigos e pela situação favorável do câmbio. $\mathrm{O}$ impulso aumentou consideravelmente quando começaram a afluir à cidade as grandes massas de emigrantes da península que, além dos gêneros alimentícios, determinaram um substancial aumento das importações de tecidos, chapéus, especialidades farmacêuticas, mármore e material de construção em geral.

Tal processo foi ulteriormente incrementado com a utilização de caixeirosviajantes a serviço das principais casas comerciais italianas, chamados "cometas", que enfrentavam as dificuldades dos transportes para estender a rede dos produtos italianos também em direção às fazendas e às colônias agrícolas no interior do Estado. Ampliouse, assim, rapidamente a rede dos trânsitos comerciais (PISANI, 1937, p. 1141-1143).

O frenético incremento demográfico e o desenvolvimento repentino das principais realidades urbanas permitiram inumeráveis oportunidades de inserção 
profissional. Exemplo disso parecia ser a descrição que Paulo Emilio de Luca traçava em relação a São Paulo em 1909:

\begin{abstract}
A categoria de emigrantes no Estado de São Paulo que se encontra em condições mais prósperas é a constituída por pessoas dedicadas ao comércio varejista e que exerce, por exemplo, pequenas oficinas, revendas de gêneros alimentícios, etc. Pode-se dizer que não há grande ou pequena cidade do Estado onde não tenha penetrado o pequeno comerciante italiano. Bem representado, entretanto, também está o grande comércio com estabelecimentos industriais grandiosos, fábricas de tecidos, de chapéus, de tijolos, de cimento, de massas, de curtumes, de serrarias, de moinhos, etc.; todavia, este permanece sempre em menor número em relação ao varejista. (DE LUCA, 1909, p. 252).
\end{abstract}

Em relação aos toscanos, o viajante de comércio que escreveu vários livros sobre países visitados da América Latina, Ubaldo Moriconi, registrava em 1897 uma predominância de indivíduos dedicados ao comércio varejista nas principais cidades e vilas dos estados do Sul do Brasil envolvidos na emigração italiana. O autor evidenciava ao mesmo tempo as vantajosas possibilidades econômicas que esse tipo de emigração podia criar nos negócios nacionais italianos, sobretudo quando se tratava de produtos alimentícios de importação como azeite e vinho (MORICONI, 1897, p. 405).

No setor específico do comércio são numerosíssimas as referências à emigração toscana e, especialmente, à "colônia de Lucca" encontrados na consulta de revistas comerciais e almanaques italianos publicados nos anos de referência. Por exemplo, no Almanacco Illustrato della Tribuna Italiana, de São Paulo, em 1905, se fazia uma referência direta aos originários de Lucca que forneceram à emigração italiana ao exterior um elemento forte "de trabalhadores incansáveis, de hábeis comerciantes, de empreendedores industriais". E continuava:

\footnotetext{
Em qualquer parte do mundo aonde tenha emigrado o nosso elemento, o originário de Lucca se destaca pela atividade da obra, pela tenacidade de propósitos, bem como pouco sabemos das belas terras banhadas pelo rio Esare que não conseguiram constituir um conveniente estado em terra estrangeira ou a voltar à pátria com uma bela quantia. (ALMANACCO, 1905, p. 749).
}

Os mesmos tons eram reutilizados nos vários almanaques que Fanfulla propunha aos seus leitores na conclusão de todo ano solar. Embora para todas as empresas iniciadas por compatriotas se utilizasse uma retórica, às vezes altissonante, relativa às capacidades e à predisposição ao trabalho dos compatriotas - tendência ainda mais evidente em época fascista -, as repetidas afirmações de habilidade comercial e de 
grande propensão à inserção nos mercados locais atribuídos à componente toscana representavam aquele que já se tornara quase um lugar-comum consolidado em relação a este grupo regional da emigração italiana. Dessa forma, podia-se ler com frequência considerações deste tipo:

[...] pertencem àquela forte e empreendedora região toscana da qual se tem tantos exemplos nas lojas de São Paulo: gente que não conhecia a morosidade, vigilante, atenta e corajosa, capaz de construir para si uma fortuna onde os outros encontram a ruína. (IL BRASILE, 1906, p. 1048).

Ou ainda: "É originário de Lucca e naturalmente tem os dotes da sua região, isto é: empreendedorismo e cautela; ponderação ao decidir os negócios e audácia ao realizálos." (CINQUANT’ ANNI, 1936, p. 359) ${ }^{3}$.

Emblemáticos também são os tons utilizados em referência ao mais importante industrialista proveniente de Lucca, Giuseppe Martinelli:

\begin{abstract}
Não à toa é de Lucca, isto é, de um tipo que acompanha o amor pela vida ativa e a devoção ao trabalho à prontidão de espírito e a habilidade de saber antecipar-se às boas oportunidades, consciente de que o mundo é de quem o pega e que no velho provérbio "ajuda-te que o céu te ajudará" está contida uma grande sabedoria. (IL BRASILE, 1906, p. 1002).
\end{abstract}

As inserções publicitárias dos principais jornais italianos no Brasil, mas também os almanaques comerciais ricos de imagens e fotografias e os próprios testemunhos epistolares dos emigrantes, permitem definir melhor aquela que devia ser a atmosfera que se respirava entre os comerciantes italianos nas ruas centrais das principais cidades.

Entre as várias atividades desse gênero, no fim do século XIX, em São Paulo despontava, por exemplo, a Brasserie Paulista, considerado um ponto de encontro importante da elite paulistana e também o principal lugar da sociabilidade internacional e multicultural presente na cidade (IL BRASILE, 1906, p. 644). Um dos proprietários era o florentino Ugo Fazzini que, sendo dono de vinhedos na sua região, importava diretamente garrafões e garrafas de vinho Chianti, junto a salames, queijos e produtos típicos toscanos (IL BRASILE, 1906, p. 1067-1068).

Outra figura que se distinguia, nos mesmos anos, era a de Gioele Bertolli, filho de Francesco Bertolli que, em Lucca, comercializava azeite toscano. Gioele foi enviado a São Paulo para ampliar os negócios da empresa paterna e ocupar-se da importação de um produto genuíno e destinado ao sucesso. Poucos anos depois, a empresa Bertolli se

\footnotetext{
${ }^{3}$ Referência a Emilio Giannini, empenhado na indústria de panificação.
} 
fundiu com a Andreotti, outra empresa de Lucca especializada no comércio atacadista de gêneros alimentícios italianos e bem cedo os seus representantes teriam alcançado também a cidade mais ao Sul, como Porto Alegre, capital do Rio Grande do Sul, o segundo estado brasileiro numericamente mais envolvido pela emigração italiana (CINQUANT'ANNI, 1937, p. 196).

De Lucca eram também os sócios Luigi Favilla e Domenico Lombardi, “dois membros gloriosos daquela laboriosa, tenaz e dura Colônia”, que possuíam depósitos permanentes de trigo e importavam diretamente gêneros alimentícios italianos e, sobretudo, toscanos. O mesmo pode-se dizer de Domenico Barsotti, originário de Lucca que, em 1889, abriu em São Paulo a confeitaria Al vino Chianti, que além da importação de produtos italianos tinha um espaço recreativo com bilhar e mesas para o jogo das cartas.

Muitos outros são os nomes de toscano que podem ser encontrados por meio da leitura de artigos de propaganda comercial no Fanfulla, o mais famoso quotidiano étnico da comunidade italiana: Nesti e Guastini, que importavam vinhos e licores nacionais, além do apreciado azeite de Lucca (FANFULLA, 20 de abril de 1897) ${ }^{4}$; Gustavo Lenci e figlio, exportador de vinhos "de refeição e de luxo" entre os quais o conhecido Chianti Cinquini (FANFULLA, 12 de agosto de 1897) ${ }^{5}$; mas também Chianti em tonéis e in "garrafas toscanas de dois litros", além do queijo pecorino da Garfagnana e dos presuntos e salames italianos ${ }^{6}$; Falchi Giannini e Cia., importadores de gêneros alimentícios, depositários do Chianti Busoni e das "maravilhosas Águas das Termas Reais de Montecatini” (ALMANACCO, 1905, p. 71); Pieri e Belli que representavam desde 1890 a empresa Bertolli de Lucca; Galileo Nieri que introduzia o Chianti Ruffino (FANFULLA, janeiro de 1898$)^{7}$; Fratelli Cinquini, importadores de vinho, queijo e azeite da Toscana (FANFULLA, 15 de abril de 1899) ${ }^{8}$; Fratelli Bonciani de Castelfiorentino, que introduziu o próprio Chianti, além do vinho da casta Aleático

\footnotetext{
${ }^{4}$ CENTRO DE AJUdA A PESQUISA DE HISTÓRIA DA UNIVERSIDADE DE SÃO PAULO. Jornais. Nesti e Guastini. Fanfulla, São Paulo, 20 abr. 1897.

${ }^{5}$ CENTRO DE AJUDA A PESQUISA DE HISTÓRIA DA UNIVERSIDADE DE SÃO PAULO. Jornais. Gustavo Lenci e figlio. Fanfulla, São Paulo, 12 ago. 1897.

${ }^{6}$ Inserções publicitárias publicadas em ALMANACCO del Fanfulla. São Paulo: s. n., 1903.

${ }^{7}$ CENTRO DE AJUDA A PESQUISA DE HITÓRIA DA UNIVERSIDADE DE SÃO PAULO. Jornais. Chianti Ruffino. Fanfulla, São Paulo, jan. 1898.

${ }^{8}$ CENTRO DE AJUdA A PESQUISA DE HISTÓRIA DA UNIVERSIDADE DE SÃO PAULO. Jornais. Fratelli Gangini. Fanfulla, São Paulo, 15 abr. de 1899.
} 
(FANFULlA, 16 de novembro de 1898) ${ }^{9}$; Francesco Papini, conhecido como um "toscano puro-sangue", que importava e revendia ao atacado produtos típicos regionais, além do vinho Chianti Ernesto Mori; bem como os Fratelli Gangini, especializados em importações de vinho e azeite e o Senhor Cavallini que, em vez, comercializava em São Paulo o vinho de Carmignano (FANFULLA, 15 de abril de 1899) ${ }^{10}$; e Nello Poli diChiesa, na província de Lucca que, tendo visitado um tio em Moçambique em 1899, transferiu-se alguns anos mais tarde para São Paulo onde trabalhou em uma refinaria de açúcar antes de abrir um ateliê de gêneros alimentícios no antigo mercadinho de São João, em uma rua central da cidade (CINQUANT'ANNI, 1937, p. 297).

Também Enrico Di Grazia, descendente da antiga e ilustre família de Veneri na província de Pistoia, em 1902, após uma experiência de atividade comercial em Chicago que lhe tinha gerado bons lucros, voltou à pátria em 1908. Ficou nela apenas três anos antes de partir novamente para o novo continente. Desta vez, escolheu o Brasil e, em especial, a cidade de São Paulo que oferecera muitas possibilidades aos seus compatriotas. Retomou, assim, uma atividade comercial dedicando-se inicialmente aos gêneros alimentícios de importação. Tendo acumulado um conspícuo capital, abriu em 1921 um estabelecimento industrial de sapatos, pantufas e tamancos, que empregava numerosos operários (CINQUANT'ANNI, 1937, p. 420).

Emblemática parecia a história de um enviado do Fanfulla que, na rubrica "Da S. Paulo a S. Paulo" de 4 de maio de 1899, percorria as ruas do centro da cidade para identificar e descrever as principais atividades desenvolvidas pelos imigrantes italianos. A Rua Boa Vista, uma das mais importantes artérias do centro, podia ser definida a "rua dos toscanos", considerando a numerosa presença de ateliês gerenciados pelos compatriotas. $\mathrm{O}$ artigo continuava:

Quatro passos mais adiante uma outra taberna muito conhecida e apreciada
para sentir necessidade de vento nas velas; pretendo falar daquela dos
senhores Pietro e Emanuel, irmãos Bonciani, que devido à longa permanência
na praça e pela qualidade dos vinhos importados das suas renomadas
vinícolas de Castel Fiorentino, adquiriu invejável fama, não só na cidade,
mas em todo o Estado. A clientela dos senhores Bonciani está entre as
melhores e o seu Chianti mantém elevado o prestígio da indústria vinícola
italiana. Após ter visitado duas tabernas é prudente mudar de ambiente muito
mais porque na última das duas se encontra um vinho santo que tiraria
facilmente os santos da reta via e um Alkermes florentino delicioso, feito

${ }^{9}$ CENTRO DE AJUDA A PESQUISA DE HISTÓRIA DA UNIVERSIDADE DE SÃO PAULO. Jornais. Fratelli Bonciani. Fanfulla, São Paulo, 16 nov. 1898.

${ }^{10}$ CENTRO DE AJUDA A PESQUISA DE HISTÓRIA DA UNIVERSIDADE DE SÃO PAULO. Jornais. Fratelli Gangini. Fanfulla, São Paulo, 15 abr. de 1899. 
para as senhoras gentis, mas usado também pelos senhores rudes. Caminhando na Rua Boa Vista se encontra a taberna de Guido Puccinelli, conhecido desde quando, no mesmo ponto, o pai exercia o mesmo comércio, enquanto o filho se deleitava de maledicência inócua. Agora Guido se tornou um jovem sério, mergulhado nos negócios e totalmente absorto na escolha de vinhos saborosos da sua Lucca. No mesmo estabelecimento não faltam licores finos e as petisqueiras que, em bom toscano, se chamam spuntini e não falta jamais a boa acolhida e o aprazível humor do proprietário e o alegre bando [...] de jovens que garante à casa um futuro próspero. (CENTRO DE AJUDA A PESQUISA DE HISTÓRIA DA UNIVERSIDADE DE SÃO PAULO, 1899). ${ }^{11}$

Na mesma rua se encontravam também o "Caffè del Serchio", uma elegante cafeteria aberta pela senhora Emma Ballerini, “onde há sempre à disposição chopes gelados, licores finíssimos e vinhos genuínos importados das melhores cantinas toscanas"; e o restaurante italianíssimo "La Giardiniera", aberto pelo florentino Francesco Regoli (FANFULLA, 24 de novembro de 1898) ${ }^{12}$.

A lista de nomes toscanos que construí por meio da utilização de fontes que surgiram seria muito mais longa, considerando também os mais modestos percursos de indivíduos que conseguiram, contudo, aproveitar o momento propício de crescimento demográfico urbano, ligado aos fluxos migratórios italianos.

Nessas lojas e ateliês mais ou menos grandes defendia-se a tipicidade regional e é importante destacar que, pelo menos até aos anos trinta do século XX, as atividades dos toscanos em São Paulo conservam quase o monopólio nas importações dos vinhos, ao passo que todo o território de Lucca, em especial, se distinguia pela exportação de azeite. Não por acaso, nas ruas da cidade, desde 1905, era inclusive distribuída gratuitamente uma revista chamada La Toscana, que todo mês difundia pequenas histórias, breves notícias de atualidade e várias anedotas ligadas à região italiana. As páginas eram repletas de publicidades relacionadas a produtos comerciais da numerosa coletividade regional presente. Abundantes eram também os anúncios que patrocinavam os artigos em venda no chamado "Empório Toscano", o principal estabelecimento de vestuário na cidade (TRENTO, 1989, p. 189).

A valorização do produto de importação genuinamente italiano acontece também no campo da moda e, mais em geral, do vestuário. O mais importante e guarnecido estabelecimento de vestuário de São Paulo, a partir de 1889, era justamente o Empório Toscano, dirigido pelos irmãos Giuseppe e Sisto Bertolucci de Lucca. Nos inumeráveis

${ }^{11}$ CENTRO DE AJUdA A PESQUISA DE HISTÓRIA DA UNIVERSIDADE DE SÃO PAULO. Jornais. A Rua Boa Vista. Fanfulla, São Paulo, 4 maio 1899.

12 CENTRO DE AJUDA A PESQUISA DE HISTÓRIA DA UNIVERSIDADE DE SÃO PAULO. Jornais. Caffèdel Serchio. Fanfulla, São Paulo, 24 nov. 1898. 
anúncios publicitários valorizava-se o fato de os tecidos em lã e em linho chegarem diretamente da Itália. O mesmo acontecia na conhecidíssima casa comercial Martini, Leonardi e Cia., cujos sócios de Lucca mantinham estreitas relações com a Itália para receber lã e algodão, bem como fazia o grande armazenamento de vestuário Alla casa di Firenze nos primeiros anos do século XX. O mesmo pode-se dizer da fabricação de chapéus que se tornou uma marca importante da emigração de Lucca e de Florença na cidade paulista. Lembram-se os casos de Giuseppe Giachi e Giovanni Cirri, Brunetto Cioni e Ferruccio Nucci que inventaram o chapéu Brasilino, quase querendo imitar o mais famoso Borsalino.

Esse setor já entrava no campo mais artesanal, pois muitas vezes requeria um trabalho delicado de entrançamento de palha com o emprego de pessoal qualificado. Frequentemente se valorizava a origem italiana da matéria-prima, palha ou feltro que fosse e, sobretudo, pelo menos nos primeiros anos, se empregavam operários italianos ou filhos de italianos.

\section{Imigração qualificada}

O setor artesanal que mais se beneficiou da influência toscana foi, porém, o da transformação da pedra e, no caso específico, do renomado mármore de Carrara. Podese afirmar que o produto "étnico" mais exclusivo e ambicionado nas cidades em expansão arquitetônica, e caracterizado pelo crescimento de uma burguesia mais atenta à qualidade dos materiais e ao valor artístico dos mesmos, foi exatamente o mármore proveniente das regiões toscanas dos Alpes Apuanos e da Versília, justamente daqueles territórios de montanha onde os deslocamentos humanos eram frequentes há muitos anos.

Um grande número de operários da região, juntamente a artesãos/artistas escultores qualificados em tal setor, exploraram habilmente as próprias capacidades e o próprio know-how, para se inserirem em um mercado totalmente novo nas principais cidades brasileiras, que requeriam incessantemente operários especializados desse tipo.

Nas páginas dos principais jornais de São Paulo apareciam frequentemente anúncios que solicitavam scalpellini, trabalhadores especializados em esculpir na pedra, hábeis na transformação do mármore. Também, nesse caso, foram determinantes os mecanismos análogos baseados nos vínculos diretos criados entre a comunidade de origem e aquela de chegada. 
Entre os primeiros fundadores da Câmara de Comércio Italiana em São Paulo, em 1902, aparece o nome do arquiteto florentino Giulio Micheli que, como presidente da Companhia Ítalo-Paulista, esteve entre os pioneiros a estimularem e ativarem o comércio do mármore de Carrara na cidade.

Frequentemente, foram implantadas em São Paulo filiais das principais empresas de mármore toscanas, nas quais se transferia, com as infraestruturas necessárias e os materiais, também o pessoal dotado de competências específicas. Em muitos casos se mantinha uma ligação contínua com a região de origem e, nos anos seguintes às primeiras gerações de emigrantes, os filhos voltavam frequentemente às escolas e academias toscanas para melhorar as habilidades técnicas antes de voltar ao Brasil com um título adquirido de grande valor e com a possibilidade de melhorar a própria empresa.

O mármore de Carrara como um produto de excelência italiana serviu também para reforçar os comércios internacionais entre os dois países. A Itália era, de fato, a única fornecedora de mármore para o Brasil e as estatísticas da Câmara de Comércio Italiana de São Paulo, nos primeiros anos do século XX, confirmavam que as principais empresas do setor eram italianas e empregavam quase totalmente mão de obra italiana, na qual se destacava aquela dos toscanos provenientes das regiões de Carrara.

Muitos são os casos de empreendedores da região que conseguiram estabelecer grandes depósitos e estabelecimentos toscanos reabastecidos continuamente com a pedra e muitíssimas também eram as pequenas empresas de artesãos e artistas, aos quais foram entregues importantes trabalhos públicos e privados nas ruas, nas praças e nos cemitérios de São Paulo.

Não nos surpreende, portanto, que o maior estabelecimento e depósito de mármore desde os últimos anos do século XIX se chamasse Marmoraria Carrara, fundada e conduzida pelo carrarês Nicodemo Roselli, que se gabava de utilizar exclusivamente pedra italiana importada, junto com as técnicas e a mão de obra, em grande quantidade dos territórios de origem; o mesmo podia se dizer da Marmoraria Tomagnini, uma filial da Giuseppe Tomagnini e fratello, de Pietrasanta, que acolheu técnicos e operários especializados originários da Versília, atraídos pelas possibilidades oferecidas por uma capital que estava se renovando totalmente do ponto de vista construtivo, arquitetônico e artístico.

Além das principais, encontrou-se a existência de dezenas e dezenas de empresas artesanais menores geridas por toscanos provenientes das regiões mineiras de mármore 
com uma bagagem preciosa de especialização e com um acentuado dinamismo que lhes permitiu adaptar-se logo às condições de um mercado em forte crescimento também nas cidades mais "periféricas" ou em outros Estados envolvidos pela imigração italiana (DE RUGGIERO, 2014, p. 81-84).

\section{Considerações finais}

Os tantos exemplos e as trajetórias pessoais identificadas relativas aos habitantes de Lucca e, mais em geral, toscanos provenientes de Garfagnana e de Lunigiana, artífices de iniciativas empreendedoras das mais modestas às mais significativas, embora não possam fornecer um modelo exato e exclusivo de interpretação, nos restituem a medida de uma incidência urbana realmente substancial, sobretudo em determinados setores profissionais, quando as cidades começaram a crescer como reflexo da expansão da fronteira do café e do incremento produtivo nos campos (CONSTANTINO, 2001).

Angelo Trento destacou em diversas ocasiões a relevância de tal processo alimentado abundantemente pela mão de obra italiana, que permitiu a introdução de novas profissões e de uma renovada cultura material. Nas principais cidades brasileiras os imigrantes inseriram-se em um mercado de trabalho "no qual muitas ocupações estavam justamente se definindo à época" e, por este motivo, "não substituíram a mão de obra local, mas preencheram espaços vazios e acabaram exercitando um verdadeiro monopólio em algumas profissões" (TRENTO, 2000, p. 77).

A análise das fontes diplomáticas e em especial as relações consulares, mas também a publicidade e a literatura de viagem utilizada, evidenciam de modo incontestável uma divisão social e profissional dos italianos no Brasil, que se repetia nos diferentes contextos de imigração. Os toscanos distinguiam-se pela ocupação nas atividades comerciais de gêneros alimentícios, vestuário e artesanato, algumas vezes artístico.

Aquilo que emergiu, também graças a algumas pesquisas incipientes sobre o caso emigratório da componente regional no Rio Grande do Sul, é uma subjetividade cultural e social da comunidade toscana que se distinguiu por uma vocação nitidamente urbana. Em determinados setores profissionais teve uma contundência bem maior em relação ao peso numérico total expresso nas comunidades ítalo-brasileiras. 
Impressiona também a capacidade desse grupo manter, em diversas ocasiões, uma ligação "transnacional" sólida com a comunidade de proveniência. Fato que favoreceu a proliferação nas principais cidades de casas de despachos, ou seja, escritórios de importação de produtos típicos regionais, não só alimentícios, como se viu. Tratava-se de uma emigração que, em muitos casos, tirava proveito das redes sociais e familiares consolidadas no tempo e, portanto, menos imprudente e mais consciente em relação ao êxodo das grandes massas camponesas que buscaram no Brasil, por vezes com resultados decepcionantes, o Paese della Cuccagna. 


\section{REFERÊNCIAS}

ALMANACCO del Fanfulla. São Paulo: s. n., 1903.

ALMANACCO illustrato della “Tribuna Italiana”. São Paulo: s. n., 1905.

AMBROSINI, Maurizio. Le formiche della globalizzazione. In: AMBROSINI, Maurizio. (Org.). Intraprendere fra due mondi. Il transnazionalismo economico degli immigrati. Bologna: Il Mulino, 2009. p. 7-14.

BIONDI, Luigi. Entre as associações étnicas e de classe. Os processos de organização política e sindical dos trabalhadores italianos na cidade de São Paulo (1890-1920). 2002. Tese (Doutorado em História Social) - Universidade Estadual de Campinas, Instituto de Filosofia e Ciências Humanas, Programa de Pós-Graduação em História, Campinas, 2002.

BRIGANTI, Lucilla. L'emigrazione toscanain America Latina tra '800 e '900. Africana: miscellanea di studi extraeuropei. Pisa: Edizione ETS, 1997. p. 41-59.

CENTRO DE AJUDA A PESQUISA DE HISTÓRIA DA UNIVERSIDADE DE SÃO PAULO. Jornais. Nesti e Guastini. Fanfulla, São Paulo, 20 abr. 1897.

CENTRO DE AJUDA A PESQUISA DE HISTÓRIA DA UNIVERSIDADE DE SÃO PAULO. Jornais. Gustavo Lenci e figlio. Fanfulla, São Paulo, 12 ago. 1897.

CENTRO DE AJUDA A PESQUISA DE HITÓRIA DA UNIVERSIDADE DE SÃO PAULO. Jornais. Chianti Ruffino. Fanfulla, São Paulo, jan. 1898.

CENTRO DE AJUDA A PESQUISA DE HISTÓRIA DA UNIVERSIDADE DE SÃO PAULO. Jornais. Fratelli Bonciani. Fanfulla, São Paulo, 16 nov. 1898.

CENTRO DE AJUDA A PESQUISA DE HISTÓRIA DA UNIVERSIDADE DE SÃO PAULO. Jornais. Fratelli Gangini. Fanfulla, São Paulo, 15 abr. de 1899.

CENTRO DE AJUDA A PESQUISA DE HISTÓRIA DA UNIVERSIDADE DE SÃO PAULO. Jornais. A Rua Boa Vista. Fanfulla, São Paulo, 4 maio 1899.

CENTRO DE AJUDA A PESQUISA DE HISTÓRIA DA UNIVERSIDADE DE SÃO PAULO. Jornais. Caffèdel Serchio. Fanfulla, São Paulo, 24 nov. 1898.

CINQUANT’ANNI di lavoro degli italiani in Brasile. Vol. I. São Paulo: S.E.I., 1936.

CINQUANT'ANNI di lavoro degli italiani in Brasile. Vol. II. São Paulo: S.E.I., 1937.

COMPANS DE BRICHANTEAU, E. Porto Alegre. Rapporto (25 marzo 1892). In: MINISTERO AFFARI ESTERI. Emigrazione e colonie. Raccolta di rapporti dei RR. Agenti diplomatici e consolari. Roma: Tip. Naz. G. Bertero, 1893. 
CONSTANTINO, Núncia Santoro de. Gli italiani nelle città. L'immigrazione italiana nelle città brasiliane. Perugia: Guerra, 2001.

CORTI, Paola. Famiglie transnazionali. In: CORTI, Paola; SANFILIPPO, Matteo (Org.). Migrazioni. Annali Storia d'Italia, 24. Torino: Einaudi, 2009. p. 303-316.

DE FORESTA, Alberto. Attraverso l'Atlantico e in Brasile. Roma: A. Sommaruga, 1884.

DE LUCA, P. E. Della emigrazione europea ed in particolare di quella italiana. vol. 2, parte segunda, "Causas ed effetti del fenomeno migratorio". Torino: Bocca, 1909.

DE RUGGIERO, Antonio. Emigranti toscani nel Brasile meridionale (1875-1914). Tese de doutorado em Estudos históricos para a idade moderna e contemporânea. Firenze: Unifi, 2011.

DE RUGGIERO, Antonio. Os empreendedores toscanos do mármorenas cidades brasileiras (1875-1914). In: FAY, Claudia Musa; DE RUGGIERO, Antonio (Org.). Imigrantes empreendedores na história do Brasil. Porto Alegre: Ed. PUCRS, 2014.

FRANZINA, Emilio. L'emigrazione nella storia d'Italia fra intraprendenza e imprenditorialità. In: DE ROSA, Ornella; VERRASTRO, Donato. Appunti di viaggio. L'emigrazione italiana tra attualità e memoria. Bologna: Il Mulino, 2007. p. 51-68.

GLI ITALIANI nel Brasile. San Paolo: s. n., 1924.

IL BRASILE e gli italiani. Firenze: Bemporad, 1906.

LOMBROSO, Gina Ferrero. Nell'America Meridionale (Brasile-UruguayArgentina). Milano: F.lliTreves, 1908.

MARTELLINI, Amoreno. Emigrazione e imprenditoria. Cinque ipotesi di studio. In: CORTI, Paola; SANFILIPPO, Matteo (Org.). Migrazioni. Annali Storia d'Italia, 24. Torino: Einaudi, 2009.p. 285-301.

MARTINELli, F. San Paolo: gli italiani. Integrazione sociale e diffusione culturale.Roma: Bulzoni, 1988.

MORICONI, Ubaldo A. Nel paese de'macachi. Torino: Roux Frassati, 1897.

OSTUNI, Maria Rosaria Dalla Valle del Serchio all'America: "Perché andiedi". In: ARCHIVIO PAOLO CRESCI PER LA STORIA DELL'EMIGRAZIONE ITALIANA. "Il perché andiedi in America...". Immagini dell'emigrazione lucchese. La Valle del Serchio. Lucca: Pacini Fazzi, 2001.

PISANI, S. Lo Stato di San paolo nel Cinquantenario dell'Immigrazione. San Paolo: s. n., 1937.

LOMONACO, A. Al Brasile. Milano: Vallardi, 1889. 
TRENTO, Angelo.La dov’è la raccolta del caffè. Padova: Antenore, 1984.

TRENTO, Angelo. Do outro lado do Atlântico. Um século de imigração italiana no Brasil. São Paulo: Nobel, 1989.

TRENTO, Angelo. Os italianos no Brasil / Gli italiani in Brasile. San Paolo: Ambasciata d'Italia; Istituto Italiano di Cultura, 2000.

VANGELISTA, Chiara. Le braccia per la fazendas. Immigrati e "caipiras" nella formazione del lavoro paulista. Milano: Franco Angeli, 1981. 